\title{
As crenças de autoeficácia de professores de Física: um instrumento para aferição das crenças de autoefi- cácia ligadas a Física Moderna e Contemporânea ${ }^{+*}$
}

\author{
Diego Marceli Rocha \\ Doutorando - USP \\ Faculdade de Educação - SP \\ Elio Carlos Ricardo \\ Faculdade de Educação - USP \\ São Paulo - SP
}

\section{Resumo}

As práticas docentes são regidas por diversos elementos, internos e externos aos indivíduos, que conduzem suas ações em sala de aula. As crenças de autoeficácia, propostas por Bandura (1986), são um interessante constructo psicológico que nos auxilia na compreensão do comportamento humano. Dessa forma, este estudo tem por objetivo apresentar um instrumento de medida das crenças de autoeficácia dos professores de física a respeito de seu trabalho com a Física Moderna e Contemporânea (FMC). Esse instrumento é um questionário composto de 21 itens, construído em uma escala Likert, e que foi aplicado a um conjunto de 78 professores de Física para a aferição dos seus níveis de crenças de autoeficácia no ensino e de crenças de autoeficácia pessoal. Através do processo de validação apresentado por Silveira (1993) obtivemos indícios de que o instrumento em questão é adequado para avaliar as cren-

\footnotetext{
+ The Self-Efficacy Beliefs of Physics Teachers: an instrument for assessment of selfefficacy beliefs related to Modern and Contemporary Physics

* Recebido: agosto de 2013. Aceito: novembro de 2013.
} 
ças de autoeficácia no ensino e as crenças de autoeficácia pessoal dos professores de física com relação à $F M C$.

Palavras-chave: Crenças de Autoeficácia. Física Moderna e Contemporânea. Questionário.

\begin{abstract}
Teaching practices are governed by many factors, both internal and external to individuals that conduct their activities in the classroom. The self-efficacy beliefs, proposed by Bandura (1986), are an interesting psychological construct that help understanding of human behavior. Thus, this study aims to present a measuring instrument of self-efficacy beliefs of Physics teachers about their work on the Modern and Contemporary Physics (MCP). This instrument is a questionnaire consisting of 21 items, built on a Likert scale, which was applied to a set of 78 Physics teachers to measure their levels of self-efficacy beliefs in teaching and personal self-efficacy beliefs. Through the validation process presented by Silveira (1993) we obtained evidence that the instrument is appropriate for assessing self-efficacy beliefs in teaching and personal self-efficacy beliefs of Physics teachers concerning the MCP.
\end{abstract}

Keywords: Self-efficacy beliefs. Modern and Contemporary Physics. Questionnaire.

\title{
I. Introdução
}

O ensino de Física, tratado nas escolas em geral, é constituído por um conjunto de instruções que se consolidaram, já há algum tempo, em práticas voltadas ao ensino da Física Clássica. Em vista desse cenário, composto por conhecimentos de até quatro séculos atrás, consideramos que o estabelecimento de conteúdos e práticas voltadas ao ensino da Física Moderna e Contemporânea (FMC) nas escolas, ainda que previstos nos documentos oficiais ( $\mathrm{PCN}$ e PCN+), devido a sua relevância para contemplação dos objetivos da educação básica, podem ser considerados uma prática inovadora, pois a sua realização é um tanto quanto modesta no cotidiano escolar. Cavalcante (1999), Ostermann e Moreira (2000), Brockington 
(2005), Ostermann e Ricci (2005), Siqueira e Pietrocola (2006) reforçam essa percepção.

Ainda que esta pouca presença da FMC seja corriqueira nas práticas docentes ou até mesmo nos livros didáticos (que apresentam a Física Moderna como mera "curiosidade" nos tópicos finais ou nos anexos de seu escopo), não se pode negar a importância que a mesma possui na formação dos alunos. Nesse sentido, o professor é peça fundamental, ainda que não seja a única, para que essa mudança de cenário ocorra.

Desse modo, na perspectiva de dar outra direção a esse cenário, tomamos o professor como agente de mudança em um contexto de inovação e encontramos na Teoria Social Cognitiva de Bandura (1986), em especial nas crenças de autoeficácia, um referencial teórico promissor para perceber as práticas docentes neste ambiente.

Bzuneck (2000), em uma revisão das pesquisas sobre as crenças de autoeficácia revela que as mesmas exercem influência sobre a motivação dos professores. Segundo o autor, os professores que desenvolveram sólidas crenças de autoeficácia demonstram atitudes e comportamentos harmoniosos, ainda que em circunstâncias adversas. Além disso, apresentam maiores níveis de comprometimento com o ensino e adotam procedimentos mais eficazes para lidar com alunos em meio a dificuldades de aprendizagem. Professores com elevados níveis de crenças de autoeficácia são mais propensos a introduzir práticas inovadoras e apresentam uma posição mais democrática em sala de aula, o que promove autonomia e confiança.

Pode-se dizer que as crenças de autoeficácia estão diretamente associadas com as práticas docentes presentes em sala de aula e, particularmente, com as práticas inovadoras. A fim de contribuirmos com a identificação e análise das crenças de autoeficácia dos professores de Física para com a FMC, bem como sua influência nas práticas docentes, apresentaremos, neste trabalho, um questionário desenvolvido para aferição das crenças de autoeficácia dos professores a respeito da inserção de tópicos de Física Moderna e Contemporânea no Ensino Médio ${ }^{1}$, bem como os indicativos de sua validade para investigações nessa área. Apresentaremos também uma revisão bibliográfica das abordagens metodológicas empregadas em pesquisas sobre o mesmo tema.

\footnotetext{
${ }^{1}$ Este trabalho constitui parte de um estudo mais amplo que visa analisar a influência das crenças de autoeficácia dos professores de Física na inserção de conteúdos ligados a FMC.
} 


\section{Crenças de autoeficácia}

De acordo com Bandura (1986), as crenças de autoeficácia são compreendidas como os "julgamentos das pessoas sobre suas capacidades para organizar e executar cursos de ação necessários para alcançar certo grau de performance" (p. 391).

As crenças de autoeficácia estão relacionadas com a percepção dos indivíduos a respeito de suas próprias capacidades de executar determinadas tarefas. As crenças de autoeficácia são a base para a motivação humana, o gerenciamento do bem-estar e a promoção das realizações pessoais. Para Pajares e Olaz (2008), as pessoas só irão investir em ações que acreditem que possam produzir os resultados desejados, caso isso não ocorra, os indivíduos terão pouco incentivo para perseverar frente às dificuldades.

Além disso, as crenças de autoeficácia influenciam nas escolhas dos indivíduos, fazendo com que os mesmos optem por realizar tarefas em que se sintam mais confiantes e competentes, como também evitem aquelas em que não se sintam dessa forma. Além disso, as crenças de autoeficácia determinam o grau de esforço e persistência que um sujeito irá aplicar na execução de uma atividade em vista dos obstáculos que advirão dessa situação. As crenças de autoeficácia influenciam também os padrões de pensamento e reações emocionais dos indivíduos, promovendo, por vezes, sentimentos de serenidade (alto nível de autoeficácia), ou de estresse e/ou depressão (baixo nível de autoeficácia) na abordagem de determinadas tarefas (PAJARES, 1996).

As crenças de autoeficácia estão fortemente configuradas com o comportamento humano, possibilitando, muitas vezes, a determinação de ações através do conhecimento de suas crenças em suas capacidades. Esse fato nos permite compreender, por exemplo, como as pessoas se comportam em vista de suas capacidades reais para executar determinada tarefa. Em muitos casos, as pessoas são capazes o suficiente para realizar determinado curso de ação, mas não o fazem em vista de uma fraca crença de autoeficácia pessoal. Ou, ainda, deparamo-nos com casos em que as pessoas não são tão qualificadas para o trabalho, mas se propõem a realizálo por deterem um forte senso de autoeficácia.

Assim, mais do que dispor das habilidades e conhecimentos para a realização de uma determinada ação, o indivíduo deveria possuir as crenças de autoeficácia em um nível suficiente para executar determinada tarefa. Todavia, é importante salientar que as crenças de autoeficácia não são suficientes para produzir o sucesso na ação de um indivíduo sem que este possua alguma habilidade ou conhecimento para tal. 
Além de orientar o comportamento humano, as crenças de autoeficácia funcionam também como uma lente que possibilita aos indivíduos internalizarem de diferentes formas as experiências vivenciadas. Indivíduos que possuem diferentes níveis de crenças de autoeficácia, quando submetidos a uma mesma experiência, podem interpretá-la de maneira distinta, de modo a promoverem ou não o aumento de suas crenças de autoeficácia.

A partir da importância dada às crenças de autoeficácia para o entendimento do comportamento humano, diversas linhas de pesquisas surgiram em diversos campos, tais como: educação, promoção da saúde, prevenção de doenças, disfunções clínicas, realizações atléticas, funcionamento organizacional, eficácia de sistemas sociais e políticos (BANDURA, 2005).

\section{Principais fontes das crenças de autoeficácia}

Bandura (1977) nos reporta a quatro fontes para a constituição das crenças de autoeficácia: as experiências positivas, as experiências vicárias, a persuasão verbal e os estados fisiológicos.

As experiências positivas são situações em que o sujeito se defronta com uma situação problemática e obtém sucesso em seu enfrentamento, permitindo-lhe, assim, obter informações de suas próprias capacidades para encarar situações similares. Situações que promovam conclusões de sucesso contribuem para o fortalecimento das crenças de autoeficácia dos sujeitos, já aquelas avaliadas como fracassos, geram uma redução no senso de autoeficácia dos indivíduos. Entretanto, é importante salientar que as crenças de autoeficácia mantidas a priori são fundamentais para a interpretação de sucesso ou de fracasso de uma determinada atividade. Indivíduos que detém um baixo nível de crença de autoeficácia tendem a superestimar o seu sucesso em determinada tarefa.

As crenças de autoeficácia influenciam o comportamento humano. Nesse sentido, podem desempenhar um papel de superestimação ou subestimação das reais capacidades do indivíduo. Para isso, é importante que se conheça a natureza das habilidades necessárias para executar determinada tarefa, a fim de que não haja discrepância entre a autoeficácia e o comportamento do indivíduo. Isso é perceptível em situações consideradas custosas, muito mais do que realmente são, e que podem promover um errôneo senso de autoeficácia. Em contrapartida, situações avaliadas como fáceis geram um excesso de confiança no indivíduo. Desse modo, os objetivos e os níveis de desempenho de uma determinada tarefa devem ser estudados para que o julgamento de autoeficácia funcione como regulador e indicador de um real desempenho (PAJARES; OLAZ, 2008). 
Dessa forma, as experiências positivas são as fontes que mais contribuem para o fortalecimento ou a destruição do senso de autoeficácia dos indivíduos, pois estas se relacionam com os componentes auto-regulatórios do comportamento humano.

As experiências vicárias estão ligadas à observação de experiências de êxito ou de insucesso de outros indivíduos em situações semelhantes que influenciam seu comportamento. As experiências vicárias são fontes de informações mais fracas do que as experiências positivas, contudo, são grandes contribuidoras para a formação das crenças de autoeficácia quando os indivíduos não têm plena convicção de suas capacidades ou, ainda, possuem vaga experiência na realização da tarefa. Pajares e Olaz (2008) atentam para o fato de que mesmo os indivíduos com altas crenças de autoeficácia aumentam sua autoeficácia quando determinados modelos ou estratégias lhes ensinam a fazer coisas de uma maneira melhor, ou ainda, que a observação de modelos com atributos semelhantes aos dos indivíduos, quando submetidos a situações de mau êxito, prejudicam as crenças dos observadores a respeito de sua própria capacidade de sucesso.

A persuasão verbal pode ser entendida como um conjunto de estímulos verbais que permitem ao indivíduo tomar consciência de que pode ou não realizar determinada tarefa. Em muitos casos, a persuasão verbal é confundida com um conjunto de elogios que proporcionam o aumento das crenças de autoeficácia do sujeito. Apesar de ser uma importante fonte na constituição das crenças de autoeficácia, a persuasão verbal contribui muito mais fortemente para o enfraquecimento das crenças de autoeficácia, por meio de persuasões negativas, do que para o fortalecimento das mesmas através de avaliações positivas.

Por fim, os estados fisiológicos contemplam as reações emocionais e fisiológicas dos indivíduos, tais como: ansiedade, estresse, aumento do batimento cardíaco, respiração ofegante, calafrios, na realização de determinada ação. Tais sinais fisiológicos informam ao sujeito a necessidade de maiores demandas para a realização de uma determinada tarefa, o que pode gerar uma perda no senso de autoeficácia. Todavia, a experiência de emoções positivas, que, em muitas das vezes, estão associadas aos mesmos estados fisiológicos, podem ser interpretadas como fontes positivas as crenças de autoeficácia do sujeito.

\section{As crenças de autoeficácia geral no ensino}

As pesquisas relacionadas às crenças de autoeficácia dos professores revelaram um novo conceito para a área. Ashton (1984) cita o trabalho anterior (ASHTON, et al., 1983) como o estudo pioneiro que derivou esse novo conceito; aquele 
de eficácia no ensino em geral. Segundo os autores, esse novo conceito de autoeficácia era equivalente, dento da perspectiva da Teoria Social Cognitiva, ao que Bandura (1977) denominou de Expectativa de Resultado. Gibson e Dembo (1984) em um estudo a posteriori, sobre as crenças dos professores, revelam também esse novo conceito, correlacionado às crenças de autoeficácia dos professores, denominado agora por autoeficácia no ensino, que novamente possui correspondência com as expectativas de resultados propostas por Bandura (1977). Ambos os estudos demonstram uma relação de interdependência entre as crenças de autoeficácia pessoal e no ensino dos professores. Por exemplo, um professor pode apresentar um elevado índice de crença de autoeficácia no ensino, no que se refere à aplicação de conteúdos de Física Moderna e Contemporânea no Ensino Médio. Entretanto, esse mesmo professor pode apresentar uma baixa crença de autoeficácia pessoal em realizar tal tarefa.

A relação entre as crenças de autoeficácia e as expectativas de resultado é fruto de incessantes debates. Pajares (1996) apresenta uma série de discussões travadas por diversos autores a respeito dessa temática. O autor apresenta uma série de estudos (ATKINSON, 1957; MCCLELLAND, 1985; ROTTER, 1982) em que os pesquisadores afirmam que a motivação dos indivíduos está intimamente relacionada com a questão do resultado esperado, de modo a não demonstrarem predisposição em executar tarefas cujos resultados não são de grande valia. Desse modo, as expectativas de resultado poderiam influenciar a motivação e o comportamento humano. Sendo assim, as expectativas de resultado estariam relacionadas com as crenças de autoeficácia, pois segundo Bandura (1986), as últimas, em parte, determinam as primeiras. Bandura (1986) afirma que os resultados esperados pelos sujeitos são dependentes de suas conclusões sobre o que elas podem realizar.

A fim de revelar outros pontos de vista, Pajares (1996) apresenta o exemplo utilizado por Marzillier e Eastman (1984) para demonstrar que as expectativas de resultado desempenham um papel considerável na formação da percepção de eficácia dos indivíduos. Nesse exemplo, um homem socialmente ansioso é convidado para participar de uma festa. Para este homem, as expectativas de resultado são desastrosas, em que as pessoas irão rir dele e que fará papel de bobo. Esse exemplo impossibilita a dissociação entre as expectativas de resultado e o julgamento de eficácia desse indivíduo. Segundo os autores, as expectativas de resultado são tão importantes para determinar a ida do homem à festa quanto a sua crença em lidar com as situações que essa ocasião demanda, sendo assim, suas percepções de eficácia são geridas a partir dos resultados imaginados. Todavia, Bandura (1984) contraria essas conclusões, fazendo uso do mesmo exemplo. Segundo ele, a decisão de participar ou não da festa que prevê resultados desastrosos está, em 
grande parte, relacionada com a pouca confiança que o homem tem em suas capacidades de lidar com as demandas desse tipo de situação, sendo assim, as expectativas de resultado são fruto da percepção da autoeficácia dos indivíduos.

É importante ressaltar que é comum entre os pesquisadores tratar diferentemente as crenças de autoeficácia pessoal no ensino e crenças de autoeficácia geral no ensino. Contudo, Woolfolk e Hoy (1990) argumentam que tais categorias não correspondem àquelas propostas por Bandura (1977). Podemos admitir que a autoeficácia pessoal equivale ao que Bandura chama de autoeficácia percebida. No entanto, o conceito de autoeficácia geral no ensino não apresentaria a menor relação com o conceito de expectativas de resultados (BZUNECK, 1996).

Além disso, Woolfolk e Hoy (1990) nos alertam para o fato de que as crenças de autoeficácia do ensino originadas no estudo de Gibson e Dembo (1984) não corresponderam, na verdade, ao conceito de expectativa de resultado, proposto por Bandura (1977), pois as crenças de autoeficácia do ensino estão ligadas às crenças dos professores a respeito do ensino, em um contexto mais geral. Essa visão generalista parece violar o conceito de Bandura, onde as crenças de autoeficácia deveriam ser avaliadas em situações bem específicas.

Essa é uma problemática muito importante dentro da perspectiva das crenças de autoeficácia, pois as mesmas devem ser avaliadas em alto nível de especificidade, o que significa uma correspondência com a tarefa de critério avaliada e o domínio do funcionamento que está sendo analisado. Entretanto, o que se verifica, em algumas pesquisas em educação, é que esse cuidado parece ser ignorado. Desse modo, os estudos revelam avaliações de crenças de autoeficácia mais gerais que, por sua vez, fornecem níveis de autoeficácia mais globais que descontextualizam a correspondência entre a autoeficácia e o comportamento humano e transformam as crenças de autoeficácia em simples traços de uma personalidade generalizada (PAJARES, 1996).

Neste trabalho, por sua vez, as questões que envolvem o ensino estão bem delimitadas, como, por exemplo, as práticas que envolvem a inserção de conteúdos de Física Moderna e Contemporânea no Ensino Médio. Acreditamos, portanto, que possamos fazer uma correspondência entre a teoria de Bandura e as crenças de autoeficácia geral no ensino mensuradas neste estudo.

Para Bzuneck e Guimarães, as crenças de autoeficácia geral no ensino são "crenças que os professores, em geral, estão aptos a atender eficazmente os desafios inerentes ao ensino" (2003, p.139). Desse modo, as crenças de autoeficácia geral no ensino se combinam com a capacidade ou com a limitação do ensino em alcançar um determinado objetivo, ainda que o professor não se sinta capaz de realizar tal atividade. É comum observarmos relatos dos professores que apontam a 
necessidade e a importância da implementação de conteúdos de Física Moderna e Contemporânea no Ensino Médio de forma mais efetiva, ainda que não se sintam capazes de realizar tal tarefa. Encontramos também professores que desacreditam e que, até mesmo, repudiam a aplicação de conteúdos que se referem à Cinemática no Ensino Médio, mas que ano após ano gastam de um a dois bimestres com essa temática, em vista de uma segurança (alta crença de autoeficácia pessoal) no domínio e na execução desse conteúdo, muito mais do que uma "suposta obrigação" curricular.

\section{IV.1 O uso de questionários nas pesquisas de crenças de autoeficácia}

O uso de questionários, constituídos por uma escala Likert, para a aferição das crenças de autoeficácia dos professores pode ser considerado uma metodologia tradicional nessa área de pesquisa. Ainda na década de oitenta, dois trabalhos da Rand Corporation $^{2}$ (ASHTON, 1984; GIBSON; DEMBO, 1984) são considerados os pioneiros no estudo das crenças de autoeficácia. Ashton (1984), em um trabalho com 48 professores do Ensino Médio, utilizou, além de entrevistas, um questionário composto por duas questões em uma escala do tipo Likert, o que lhe possibilitou identificar duas ramificações das crenças de autoeficácia, denominadas: eficácia do ensino e autoeficácia pessoal no ensino. As questões apresentadas eram as seguintes:

i) Quando a aprendizagem dos alunos vai mesmo mal, um(a) professor(a) não pode fazer muito porque a maior parte da motivação e desempenho do aluno depende de seu ambiente no lar.

ii) Se eu realmente me empenhar com afinco, posso dar conta até dos alunos mais difíceis ou desmotivados ${ }^{3}$.

Gibson e Dembo (1984) desenvolveram um instrumento para aferição da medida de autoeficácia dos professores com alunos considerados difíceis. Esse instrumento era composto por 30 itens numa escala Likert, e foi aplicado a um conjunto de 208 professores do Ensino Fundamental. Nesse, estudo os pesquisado-

\footnotetext{
2 A Rand Corporation é uma instituição sem fins lucrativos, localizada em Santa Mônica na Califórnia, que tem por princípio básico fazer uso de pesquisas nas diversas áreas como educação, negócios, saúde, direito e ciência para a melhoria política e a tomada de decisões através das investigações. Informações em: 〈http://www.rand.org>.

${ }^{3}$ Tradução apresenta por Bzuneck (1996).
}

Caderno Brasileiro de Ensino de Física, v. 31, n. 2, p. 333-364, ago. 2014. 
res observaram que os professores que apresentam maiores níveis de senso de autoeficácia são mais propícios a ensinar os alunos considerados difíceis, além do fato de se julgarem profissionais passíveis de envolver a família dos estudantes junto ao ambiente escolar. Em contrapartida, aqueles professores que demonstraram níveis mais baixos com relação à autoeficácia no ensino, relataram o sentimento de incapacidade de fazer algo por seus alunos e que a inserção da família junto ao ambiente escolar é fator irrelevante no desenvolvimento intelectual dos alunos.

Parkay et al. (1988), utilizando-se do teste proposto por Ashton (1984) com professores da rede pública, observaram que os docentes que acreditavam exercer algum tipo de influência sobre seus alunos apresentavam menores níveis de estresse e demonstravam uma maior desenvoltura no desenvolvimento de estratégias para lidar com esse tipo de situação, além de exibirem uma melhor relação com seus pares, com os alunos e seus pais.

Riggs e Enochs (1990) desenvolveram dois instrumentos para a mensuração das crenças de autoeficácia entre professores de Ciências do Ensino Básico, a saber, STEBI-A e STEBI-B. O STEBI-A (Science Teaching Efficacy Belief Instrument) é constituído por vinte e cinco itens, em uma escala do tipo Likert, com o intuito de medir as crenças de autoeficácia dos professores em exercício. O STEBIB é composto por vinte e três questões que, por sua vez, buscavam observar as crenças de autoeficácia dos professores em formação. Este estudo, em especial, permitiu a quantificação das crenças de autoeficácia pessoal e de ensino em diferentes fases da carreira docente.

Woolfolk e Hoy (1990), baseados nos trabalhos de Gibson e Dembo (1984), elaboram um novo instrumento de medida das crenças de autoeficácia docente. Este novo questionário era composto por vinte e duas questões, sendo dez delas confeccionadas para se medir a autoeficácia no ensino e as doze restantes para se medir a autoeficácia pessoal. $\mathrm{O}$ instrumento, também como o de Gibson e Dembo (1984), foi estruturado através de uma escala do tipo Likert, só que agora numa escala de seis pontos, variando desde "concordo plenamente" até "discordo plenamente".

Coladarci (1992), em um estudo com professores do Ensino Fundamental, lançou mão de três questionários para a identificação dos fatores influentes no comprometimento desses professores com o ensino e qual a relação com o desejo de permanência na profissão. Além disso, buscou verificar se a escolha da profissão docente possui alguma ligação com as crenças de autoeficácia dos professores. O primeiro instrumento utilizado foi uma única questão na escala Likert de cinco pontos onde se avaliava a possibilidade do docente escolher novamente o ensino como profissão. A seguir foi aplicado o teste de Gibson e Dembo (1984), com 
ligeiras alterações. E, por fim, um novo questionário foi construído com trinta questões, a fim de se obterem dados correlacionados ao companheirismo entre os pares.

Guskey e Passaro (1994) apresentaram um novo instrumento de medida das crenças de autoeficácia dos professores. Para tal, os autores realizaram algumas adaptações no questionário de Gibson e Dembo (1984), além de adicionarem a este três itens dos trabalhos de Woolfolk e Hoy (1990) e mais dois itens das pesquisas da Rand Corporation. O questionário final era composto por vinte e um itens, confeccionado numa escala Likert de seis pontos, variando desde "concordo plenamente" até "discordo plenamente".

Goddard et al. (2000) produziram um instrumento para a medição do constructo de eficácia coletiva nas escolas. Para a construção desse novo instrumento de medida, os autores dispunham de dezesseis itens do instrumento de Gibson e Dembo (1984). Todavia, realizaram modificações nas questões do questionário original, que dispunham um olhar mais individual, a fim de dar às questões uma orientação coletiva. Assim, o teste final era composto por vinte e um itens, em uma escala Likert de seis pontos, variando desde "concordo plenamente" até "discordo plenamente". Este instrumento foi aplicado a 452 professores e 7.016 alunos de quarenta e sete escolas primárias de uma região urbana do Estado de Maine nos Estados Unidos.

Tschannen-Moran e Hoy (2001), na busca de um novo instrumento para medir as crenças de autoeficácia dos professores, realizaram três estudos para o desenvolvimento deste novo instrumento, denominado de Eficácia dos Professores do Estado de Ohio (OSTES). Após diversas aplicações e revisões do teste, ou autores produziram um questionário composto por um total de vinte e quatro itens, sendo oito deles contemplados em três fatores correspondentes à eficácia dos professores no uso de estratégias de ensino, à eficácia no gerenciamento de situações imprevistas e à eficácia em conseguir engajamento dos alunos.

Friedman e Kass (2002), baseados no referencial teórico de Cherniss $(1993)^{4}$ e de Bandura $(1997)^{5}$ realizaram sua investigação em Israel com a participação de 555 professores, com idade média de 34,9 anos e tempo médio de serviço

\footnotetext{
${ }^{4}$ Nesse referencial observa-se o contexto escolar e as relações interpessoais dos professores a partir de três dimensões: o conceito de crença do professor, sua autoeficácia profissional e seu trabalho de ensinar; as relações interpessoais; e a forma de organização do trabalho do professor e da escola.

${ }^{5}$ Nesse referencial Bandura retrata a necessidade de se medir as crenças de autoeficácia dos professores separando destes os processos organizacionais das instituições.
} 
de 10,8 anos. Friedman e Kass (2002) aplicaram a esse conjunto de professores um questionário composto por trinta e três questões, com respostas variando desde "nunca" (1) até "sempre" (2). Com o auxílio da análise fatorial, os autores puderam encontrar dois fatores relevantes aos diferentes contextos. O primeiro se estabelece correlacionado ao contexto de sala de aula, onde o senso de eficácia profissional possui alguma relação com a forma de ensinar, educar e motivar os alunos. O segundo fator, por sua vez, relaciona-se ao contexto da escola em si. Neste último fator podemos encontrar questionamentos voltados às tarefas realizadas na escola e às decisões tomadas para o bem-estar da mesma e suas políticas educacionais.

Çakiroglu et al. (2005) compararam as diferentes crenças de autoeficácia de professores de Ciências, ainda em formação, de uma Universidade na Turquia e de uma grande Universidade do centro-oeste dos Estados Unidos, com o objetivo de conhecer melhor as crenças de autoeficácia dos professores turcos e apresentar as diferenças e desigualdades das crenças dos futuros professores de dois países diferentes. Como instrumento de coleta de dados, os pesquisadores fizeram uso do STEBI-B (RIGGS; ENOCHS, 1990), que foi traduzido para o turco, com o auxílio de duas professoras bilíngues e, em seguida, aplicado em um estudo piloto, observando e verificando, assim, a eficiência desse instrumento.

Bembenutty (2006) realizou um estudo com o objetivo de analisar uma possível associação entre as crenças de autoeficácia dos professores em formação e seu desempenho acadêmico, ambas mediadas por suas crenças de autoeficácia sobre seus trabalhos de casa e a utilização de sua auto-regulação no uso de estratégias de aprendizagem. Dentre os vários instrumentos utilizados para a coleta de dados, destacamos o uso do teste de OSTES produzidos por Tschannen-Moran e Hoy (2001).

Smolleck e Yoder (2008) desenvolveram um instrumento denominado Teaching Science Inquiry (TSI), concebido para medir as crenças de autoeficácia dos professores em formação. O questionário foi modelado a partir dos itens que compõem o STEBI-A e STEBI-B (RIGGS; ENOCHS, 1990) e é composto por sessenta e nove itens, em uma escala do tipo Likert com cinco níveis, variando desde "concordo plenamente" até "discordo plenamente". O instrumento foi construído de modo a contemplar cinco dimensões no ensino de Ciências; são elas: i) O envolvimento científico do aluno se dá através da orientação de perguntas; ii) $\mathrm{O}$ aluno dá prioridade às evidências ao responder as perguntas; iii) $\mathrm{O}$ aluno formula explicações através das evidências; iv) $\mathrm{O}$ aluno é capaz de estabelecer ligações entre as explicações e o conhecimento científico; v) $\mathrm{O}$ aluno se comunica e justifica suas explicações. 
Eren (2009), em seu estudo, utilizou o Teacher Efficacy Scale for Prospective Teachers (TESPT) (DENZINE et al., 2005) para avaliar as crenças de autoeficácia dos professores. Esse instrumento foi construído em uma escala Likert de seis pontos variando desde "discordo plenamente" até "concordo plenamente", e sua construção foi baseada em três fatores: a opinião dos professores sobre suas crenças de autoeficácia; expectativas de resultados e locus externo de causalidade.

No Brasil, Bzuneck (1996) traduziu e utilizou em sua pesquisa a escala de Woolfolk e Hoy (1990) com vinte itens numa escala Likert de seis pontos, variando desde a "discordância total" até a "inteira concordância". Participaram dessa pesquisa 529 professores do Ensino Fundamental da rede pública. O estudo tinha como objetivos: i) avaliar o nível de crenças de autoeficácia e eficácia relacionadas ao ensino de um grande conjunto de professores; ii) observar a existência de uma diferença entre essas medidas quanto à diferença de séries em que estes professores estão inseridos; iii) verificar a relação das respectivas medidas com fatores como: idade cronológica, tempo de magistério, nível de formação acadêmica e número de alunos por turma.

Em outro estudo, Bzuneck e Guimarães (2003) revelaram as propriedades psicométricas da escala de Woolfolk e Hoy (1990), em sua versão brasileira, através do uso de técnicas de análise fatorial exploratória.

Fregoneze (2000) pesquisou as crenças de autoeficácia e percepções de um grupo de professores brasileiros envolvidos num contexto de reestruturação curricular do Ensino Médio. Dentre os vários instrumentos utilizados para a coleta de dados, chamamos a atenção para o uso de um questionário do tipo Likert composto por vinte e três itens, variando numa escala de cinco pontos, construído a partir do questionário de Avaliação de Crenças de Eficácia de Professores proposta por Woolfolk e Hoy (1990).

Luppi (2003) investigou oito escolas de diferentes contextos de Ensino Fundamental do Norte do Paraná, a fim de conhecer os níveis de crenças de autoeficácia pessoal, autoeficácia no ensino e eficácia coletiva dos professores, além de relacioná-las com o tempo de magistério de cada docente. Buscou-se também avaliar o desejo de permanência dos professores em continuar seu trabalho com ensino. Participaram dessa pesquisa 147 professores, que foram submetidos a um único questionário composto por trinta e nove itens, construído a partir de três outros instrumentos (WOOLFOLK; HOY, 1990; COLADARCI, 1992; GODDARD et al., 2000).

Com relação à investigação das crenças de autoeficácia dos professores de Física que fazem uso de questionários com escala Likert, destacamos o trabalho de Goya et al. (2008) que realizaram um estudo com o objetivo de medir as crenças 
de autoeficácia de um conjunto de professores de Física do Ensino Médio, conjuntamente com a motivação para aprender de seus respectivos alunos, de forma a tentar encontrar algum tipo de relação entre as duas variáveis. Para tal, foram empregados dois instrumentos para a realização desse estudo. O primeiro foi a versão brasileira da escala de Woolfolk e Hoy (1990), e o segundo instrumento foi o utilizado por Locatelli (2004) na avaliação da motivação dos alunos para com a Física e o seu uso de estratégias no estudo.

É relevante mencionar também o trabalho de Silva (2007), que analisou as crenças de autoeficácia de 136 professores de Física do Ensino Médio na tentativa de identificar os possíveis fatores de influência sobre suas crenças de autoeficácia pessoal e crenças de eficácia geral no ensino de Física. Investigou também possíveis influências da formação acadêmica, idade e tempo de serviço nas crenças de autoeficácia desses professores. Para contemplar tais objetivos em vista da escassez de trabalhos voltados para o estudo da motivação no ensino de Física, o pesquisador, elaborou um questionário para a realização de sua pesquisa. A elaboração do novo instrumento se deu a partir da adaptação de dois outros instrumentos já existentes: a versão brasileira do instrumento elaborado por Woolfolk e Hoy (1990), utilizado por Bzuneck e Guimarães (2003), e a versão original do STEBI-A confeccionado por Riggs e Enochs (1990). Assim, o autor produziu um questionário composto por 34 itens, construído em uma escala do tipo Likert de cinco pontos, variando desde "concordo plenamente" até "discordo plenamente".

\section{IV.2 Questionário}

Para a construção de um questionário que buscasse aferir o nível das crenças de autoeficácia pessoal e no ensino dos professores com relação à FMC, baseamos-nos no teste construído por Silva (2007), que avaliava o nível das crenças de autoeficácia dos professores de Física. Contudo, como nosso trabalho visava olhar para uma dimensão bastante específica do ensino de Física, aquela que se refere à FMC, tivemos que lançar mão de outra metodologia, além da adaptação do questionário de Silva (2007), para a construção de nosso questionário.

Em um estudo exploratório, que contou com a participação de 77 professores de Física matriculados em um curso de formação continuada em FMC oferecido pela Universidade de São Paulo, buscamos ouvir dos professores, através de 
um questionário aberto ${ }^{6}$, quais eram as suas principais concepções a respeito da FMC e o seu trabalho em sala de aula.

Como fizemos uso de um questionário aberto, obtivermos inúmeras respostas que remetiam aos mais diversos aspectos do trabalho com FMC em sala de aula. Assim, classificamos as concepções que eram apresentadas com maior frequência entre os entrevistados. As principais concepções reveladas pelos sujeitos foram: os conceitos de FMC são abstratos; a dificuldade de compreensão da relação existente entre a Física Clássica e a FMC; a visualização dos conceitos de FMC no cotidiano do aluno; a necessidade da utilização de experimentos ligados a FMC; a relação entre a FMC e o seu formalismo matemático; a dificuldade de compreensão pelos alunos dos conceitos ligados a FMC; a produção de problemas e exercícios voltados para as temáticas de FMC; a dificuldade em selecionar os conteúdos de FMC para o trabalho em sala de aula; a dificuldade de compreensão por parte do professor dos conceitos ligados a FMC; a possível motivação dos alunos para aprender sobre FMC; a necessidade de inovar para o trabalho com FMC.

Conhecidas as principais concepções dos professores de Física com relação à FMC, buscamos classificá-las em dois grupos: aquelas que se referiam a FMC como conhecimento instituído, e o segundo, ao trabalho com FMC em sala de aula. $\mathrm{O}$ primeiro grupo nos auxiliou a confeccionar as questões pertencentes às crenças de autoeficácia no ensino, já o segundo grupo de concepções nos auxiliou na construção das questões ligadas às crenças de autoeficácia pessoal ${ }^{7}$.

Assim, construímos um questionário para aferição das crenças de autoeficácia dos professores de Física a respeito da FMC composto por vinte e três questões, estruturado por uma escala do tipo Likert, de cinco níveis, desde "concordo plenamente" até "discordo plenamente".

As vinte e três questões são divididas em dois grupos:

i) As questões 1, 2, 3, 4, 5, 6, 7, 8, 9, 10, 11, 12 e 13 aferem as crenças de autoeficácia geral no ensino (CAEE); tais questões foram formuladas a respeito da compreensão de que os professores têm com relação à inserção de tópicos de FMC

\footnotetext{
${ }^{6}$ O questionário aberto, utilizado no estudo exploratório, contava com uma única questão. Nesta questão era solicitada aos professores a descrição dos fatores que contribuíam ou não para a inserção de tópicos de FMC em suas aulas de Física.

${ }^{7}$ Uma primeira versão do questionário pode ser encontrada em Rocha e Marques Filho (2011).
} 
no Ensino de Física. A seguir apresentaremos as questões que compõem o primeiro grupo:

01. Acredito que os tópicos de Física Moderna e Contemporânea são muito abstratos e dificilmente entendidos pelos estudantes.

02. As teorias da Física Moderna e Contemporânea surgiram a partir da incapacidade das teorias da Física Clássica de interpretar alguns resultados experimentais.

03. Uma dificuldade a ser enfrentada na introdução de tópicos de Física Moderna e Contemporânea no Ensino Médio é o fato de seus fenômenos não estarem acessíveis no cotidiano, nem serem passíveis de apresentação em laboratórios didáticos por meio de experimentos simples.

04. É possível ensinar tópicos de Física Moderna e Contemporânea no Ensino Médio, mesmo deixando de lado, evidentemente, seu formalismo matemático original.

05. O fato de que os conceitos presentes na Física Moderna e Contemporânea rompem com ideias cotidianas representa um obstáculo ao processo de ensino e aprendizagem dos mesmos.

06. Acredito que uma das dificuldades de ensinar tópicos de Física Moderna e Contemporânea é o fato de que seus objetos de estudo não estão presentes em nossa percepção cotidiana.

07. Não acredito ser possível ensinar tópicos de Física Moderna e Contemporânea no Ensino Médio.

08. Acredito que para se ensinar tópicos de Física Moderna e Contemporânea deva-se iniciar pelos conceitos clássicos até chegar aos modernos.

09. Os professores de Física acreditam que o ensino de Física Clássica deva necessariamente anteceder o ensino de tópicos de Física Moderna e Contemporânea.

10. Acredito que o ensino mais eficaz de Física ocorre através da proposição de problemas e exercícios.

11. Os professores de Física, em geral, acreditam que inovar os conteúdos de Física em sala de aula é algo desnecessário. 
12. Acredito que só é possível se ensinar tópicos de Física Moderna e Contemporânea a partir da apresentação de problemas e uso de equações.

13. Eu considero que só é possível avaliar a aprendizagem dos estudantes de Física Moderna e Contemporânea a partir da resolução de problemas fechados.

ii) As questões 14, 15, 16, 17, 18, 19, 20, 21, 22 e 23 aferem as crenças de autoeficácia pessoal (CAEP); estas questões visam mensurar o sentimento de capacidade dos professores a respeito de seu trabalho com a FMC em sala de aula. Para a formulação dessas questões levamos em conta que a crenças de autoeficácia são consideradas como julgamentos de nossas capacidades pessoais (BANDURA, 2005), assim, construímos questões que permitem aos sujeitos refletir a respeito da seguinte expressão: “Eu sou capaz de...”.

A seguir, apresentaremos as questões correspondentes as CAEP:

14. Eu me considero capaz de implementar inovações curriculares em meu ensino.

15. Eu não sou muito eficaz em desenvolver atividades inovadoras em sala de aula.

16. Acredito que sou capaz de selecionar conteúdos adequados para se inserir tópicos de Física Moderna e Contemporânea com meus estudantes.

17. Eu me considero capaz de ensinar tópicos de Física Moderna e Contemporânea para meus estudantes.

18. Eu me considero capaz de compreender conceitos de Física Moderna e Contemporânea.

19. Eu me considero capaz de transpor para o Ensino Médio os tópicos de Física Moderna e Contemporânea aprendidos na graduação.

20. Eu sou capaz de criar atividades de ensino de Física Moderna e Contemporânea em sala de aula.

21. Eu sou capaz de motivar meus estudantes através do ensino-aprendizagem de tópicos de Física Moderna e Contemporânea.

22. Eu sou capaz de responder as perguntas dos estudantes sobre Física Moderna e Contemporânea em sala de aula. 
23. Eu me considero capaz de tornar claros os conceitos da Física Moderna e Contemporânea aos meus estudantes.

Para a quantificação dos itens do questionário atribuímos a pontuação igual a 5 para o nível máximo de aceitação, de modo a possuir uma correlação com uma postura positiva por parte do professor a respeito de sua crença de autoeficácia, enquanto que o nível mínimo 1 sempre está relacionado com uma opinião negativa.

\section{Resultados}

O questionário foi aplicado a um conjunto de setenta e oito professores de Física do Ensino Médio participantes de um curso de formação continuada de professores, com o tema Física Moderna e Contemporânea, realizado por um grupo de pesquisa da Universidade de São Paulo, com início em agosto de $2010^{8}$.

A quantidade de professores participantes dessa pesquisa é significativa para a validação desse instrumento. Segundo Silveira (1993), para a validação de um instrumento é necessário um número de participantes igual a cinco vezes o número de questões. O número de participantes foi suficiente para validarmos o instrumento, pois esta etapa se dividiu em duas fases: validação dos itens referentes às CAEE e os itens referentes às CAEP.

Para realizar o processo de validação desse instrumento, baseamo-nos no trabalho de Silveira (1993). O autor aponta três formas de validar instrumentos de medida psicoeducacionais. Estas formas são complementares e idealmente é desejável que as três sejam efetivadas. São elas: validação de conteúdo, validação de critério e validação de constructo.

\section{1 Validação de Conteúdo}

Nessa primeira etapa colocamos em confronto os itens constituintes do instrumento de coleta de dados com a teoria que os originou. Com isso, temos a devida certificação de coerência entre os itens que compõem o questionário e o referencial teórico que os suporta.

Para satisfazer esse primeiro procedimento de validação, Silveira (1993) sugere que os itens passem pelo julgamento de alguns especialistas no conteúdo do

${ }^{8}$ O questionário foi aplicado aos professores no primeiro dia do curso.

Rocha, D. M. e Ricardo, E. C. 
instrumento, em busca de um consenso intersubjetivo entre a coerência dos mesmos com a teoria.

Construídos os itens que compõem o questionário esse foi submetido à avaliação de três especialistas com experiência em pesquisa em Educação, sendo que os mesmos deram o seu parecer favorável às questões formuladas.

\section{V.2 Validação de Critério}

Após obtermos a certificação da validade do conteúdo do instrumento, passamos para a fase de validação de critério. Nessa etapa, busca-se encontrar de forma empírica a existência de uma relação entre o constructo que se deseja medir com o instrumento e uma outra variável relevante (SILVEIRA, 1993). Entretanto, se a variável medida possuir natureza distinta daquela que se pretende validar, a validação se dará através de uma validação preditiva.

Para cumprir essa etapa de validação submetemos as respostas dos professores a uma Análise de Consistência Interna que envolve o cálculo do coeficiente de fidedignidade do escore total no instrumento e o cálculo dos coeficientes de correlação item-total. A estimativa do coeficiente de fidedignidade que adotamos é o Coeficiente Alfa de Cronbach (CRONBACH, 1967).

O Coeficiente Alfa de Cronbach é uma medida da consistência interna de um instrumento. Dessa forma, o coeficiente estima a proporção da variância do escore total no conjunto de itens que é atribuída à variável latente (fator comum) subjacente a todos os itens; portanto o seu valor máximo é igual à unidade. Para Maroco e Garcia-Marques (2006), “a consistência interna estima a fiabilidade de um instrumento porque quanto menor é a variabilidade de um mesmo item numa amostra de sujeitos, menor é o erro de medida que este possui associado" (p. 73).

O coeficiente de correlação item-total observado quantifica a relação entre duas variáveis. O coeficiente de correlação varia entre $+1,00$ e $-1,00$. Quando o coeficiente atinge o valor $+1,00$ temos uma correlação positiva e perfeita entre as variáveis de estudo, onde a variação de uma delas está associada perfeitamente à variação da outra; se uma delas cresce (decresce) a outra cresce (decresce) também. Quando o coeficiente atinge o valor -1,00 a variação de uma delas está associada perfeitamente à variação da outra, mas agora quando um delas cresce (decresce) a outra decresce (cresce). Um coeficiente de correlação nulo indica a ausência na relação entre as variáveis, isto é, a covariância entre elas inexiste (MOREIRA, 1990). 
Contamos com o auxílio do pacote PASW Statistics $18^{9}$ para os cálculos dos coeficientes e dos seus respectivos níveis de significância estatística. Os procedimentos foram realizados separadamente sobre os dois conjuntos de itens: os itens que medem as crenças de autoeficácia geral no ensino e os itens que medem as crenças de autoeficácia pessoal.

Apresentaremos, primeiramente, os resultados para as CAEE:

Tabela 1 - Correlação Item-Total e o Alfa de Cronbach para as CAEE

\begin{tabular}{|c|c|c|}
\hline \multicolumn{3}{|c|}{ CAEE } \\
\hline ITENS & $\begin{array}{l}\text { CORRELAÇÃO } \\
\text { ITEM-TOTAL }\end{array}$ & $\begin{array}{l}\text { ALFA CRONBACH, } \\
\text { se o item for excluído }\end{array}$ \\
\hline 1 & 0,272 & 0,724 \\
\hline 2 & $-0,037$ & 0,757 \\
\hline 3 & 0,555 & 0,681 \\
\hline 4 & 0,278 & 0,720 \\
\hline 5 & 0,506 & 0,689 \\
\hline 6 & 0,354 & 0,712 \\
\hline 7 & 0,438 & 0,706 \\
\hline 8 & 0,460 & 0,698 \\
\hline 9 & 0,424 & 0,702 \\
\hline 10 & 0,369 & 0,709 \\
\hline 11 & 0,143 & 0,738 \\
\hline 12 & 0,572 & 0,695 \\
\hline 13 & 0,427 & 0,643 \\
\hline
\end{tabular}

O software nos forneceu um Alfa de Cronbach igual a 0,728, um número consideravelmente satisfatório ${ }^{10}$. Contudo, Silveira (1993) sugere que sejam excluídos os itens que apresentarem uma correlação item-total próxima à zero. Sendo assim, baseamo-nos no trabalho de Silva (2007), que também realizou a validação de um instrumento que mede as crenças de autoeficácia dos professores de Física,

9 O PASW Statistics 18 é um software utilizado para a análise dos dados estatísticos.

10

A razão de concluirmos que o índice encontrado é considerado satisfatório é baseada na afirmação de Moreira (1990) que revela que estudos na área de atitudes e interesses, onde os dados são mais flexíveis, correlações da ordem de 0,7 são consideradas aceitáveis. 
e excluímos os itens que apresentam correlação item-total menores que 0,20. Dessa forma, eliminamos as questões 2 e 11.

Após a eliminação encontramos os seguintes valores:

Tabela 2 - Correlação Item-Total e o Alfa de Cronbach para as CAEE, após a eliminação dos itens 2 e 11 .

\begin{tabular}{|c|c|c|}
\hline \multicolumn{3}{|c|}{ CAEE } \\
\hline ITENS & $\begin{array}{c}\text { CORRELAÇÃO } \\
\text { ITEM-TOTAL }\end{array}$ & $\begin{array}{l}\text { ALFA CRONBACH, } \\
\text { se o item for excluído }\end{array}$ \\
\hline 1 & 0,368 & 0,759 \\
\hline 3 & 0,593 & 0,724 \\
\hline 4 & 0,292 & 0,763 \\
\hline 5 & 0,536 & 0,734 \\
\hline 6 & 0,357 & 0,761 \\
\hline 7 & 0,410 & 0,753 \\
\hline 8 & 0,460 & 0,745 \\
\hline 9 & 0,372 & 0,755 \\
\hline 10 & 0,345 & 0,759 \\
\hline 12 & 0,536 & 0,743 \\
\hline 13 & 0,436 & 0,750 \\
\hline
\end{tabular}

Realizadas as eliminações, o novo Alfa de Cronbach passa a ser igual a 0,768, valor este classificado como tendo fiabilidade apropriada, pois seu valor é superior a 0,70 (NUNNALLY, 1967).

Para as CAEP encontramos os seguintes resultados:

Tabela 3 - Correlação Item-Total e o Alfa de Cronbach para as CAEP

\begin{tabular}{ccc}
\hline \multicolumn{3}{c}{ CAEP } \\
\hline & CORRELAÇÃO & ALFA CRONBACH, \\
ITENS & ITEM-TOTAL & se o item for excluído \\
\hline 14 & 0,662 & 0,864 \\
15 & 0,589 & 0,876 \\
16 & 0,690 & 0,866 \\
17 & 0,685 & 0,864 \\
18 & 0,644 & 0,869 \\
19 & 0,599 & 0,870
\end{tabular}

Caderno Brasileiro de Ensino de Física, v. 31, n. 2, p. 333-364, ago. 2014. 


\begin{tabular}{lll}
20 & 0,535 & 0,874 \\
21 & 0,626 & 0,869 \\
22 & 0,633 & 0,867 \\
23 & 0,623 & 0,867 \\
\hline
\end{tabular}

O Alfa de Cronbach para os itens que correspondem às CAEP é 0,880 . Assim, utilizando os mesmos critérios para os itens das CAEE decidimos não eliminar nenhum item desse constructo.

\section{V.3 Validação do Constructo}

A validação de constructo pode ser fundamentada através da testagem de hipóteses que expressam a relação, ou sua ausência, de uma variável com outra, ou com outros constructos. Segundo Silveira (1993) a construção das hipóteses, que serão testadas, é baseada na teoria ${ }^{11}$, que permite prever como o constructo medido se relaciona com uma determinada variável.

Como as crenças de autoeficácia se manifestam em contextos específicos, e não encontramos na literatura estudos que fazem referência às crenças de autoeficácia pessoal e autoeficácia no ensino de professores ligados à FMC, construímos hipóteses de forma arbitrária de modo a tentar relacionar algumas variáveis, como, idade, formação acadêmica, formação complementar, tempo de magistério, tempo ministrando aulas de Física e carga horária semanal, com os diferentes níveis de CAEP e CAEE apresentados pelos sujeitos de pesquisa.

Assim, as hipóteses para a validação de constructo foram:

1) A idade é um fator que promove diferenças entre os níveis de CAEP dos professores.

2) A idade é um fator que não promove diferenças entre os níveis de CAEE dos professores.

3) A carga horária semanal promove diferenças entre os níveis de CAEE dos professores.

4) O tempo de magistério é um fator que promove diferenças entre os níveis de CAEP dos professores.

5) O tempo de magistério é um fator que não promove diferenças entre os níveis de CAEE dos professores.

${ }^{11}$ Neste caso, referimo-nos à teoria das crenças de autoeficácia.

Rocha, D. M. e Ricardo, E. C. 
6) O tempo que os professores ministram aulas de Física é um fator que promove diferenças entre os níveis de CAEP dos professores.

7) A formação acadêmica promove diferenças entre os níveis de CAEP dos professores.

8) A formação acadêmica não promove diferenças entre os níveis de CAEE dos professores.

9) Professores que possuem alguma formação complementar apresentam diferentes níveis de CAEP.

Definidas as hipóteses, realizamos os cálculos do coeficiente de correlação ordinal de Spearman entre os escores das CAEE e CAEP conjuntamente com as variáveis mencionadas anteriormente.

$\mathrm{O}$ coeficiente de Spearman resulta necessariamente entre +1 e -1 ; quanto mais próximo do índice +1 tanto mais perfeita é a variação concomitante dos escores de ordem (rank) entre as duas variáveis. Quando o coeficiente de Spearman se aproxima de -1 então a ordenação crescente de uma das variáveis está associada à ordenação decrescente da outra variável.

É comum encontrarmos testes de correlação linear que se utilizam do coeficiente de correlação de Pearson, que faz uso dos valores reais das variáveis. Já o coeficiente de correlação de Spearman lança mão apenas dos escores de ordem (rank) das duas variáveis. Portanto, o coeficiente de Spearman possui pressupostos menos restritivos do que o de Pearson e, por isso, o preferimos.

Antes de realizarmos o cálculo do coeficiente de correlação de Spearman tivemos que atribuir escores de ordem as diferentes categorias das variáveis. A seguir apresentamos esses ordenamentos:

Tabela 4 - Ordenamento para Idade.

\begin{tabular}{cc}
\hline Idade (anos) & $\begin{array}{c}\text { Escore de } \\
\text { ordem }\end{array}$ \\
\hline $0-20$ & 1 \\
$21-25$ & 2 \\
$26-30$ & 3 \\
$31-35$ & 4 \\
$36-40$ & 5 \\
$41-45$ & 6 \\
$46-50$ & 7
\end{tabular}

Caderno Brasileiro de Ensino de Física, v. 31, n. 2, p. 333-364, ago. 2014. 


\begin{tabular}{ccc}
$\begin{array}{c}51-55 \\
\text { Mais de 55 }\end{array}$ & 8 \\
Tabela 5 - Classificação para Carga Horária Semanal \\
\cline { 2 - 3 } & & 9 \\
\hline C. Horária (h) & $\begin{array}{c}\text { Escore de } \\
\text { ordem }\end{array}$ \\
\hline $0-10$ & 1 \\
$11-20$ & 2 \\
$21-30$ & 3 \\
$31-40$ & 4 \\
$41-50$ & 5 \\
$51-60$ & 6 \\
$61-70$ & 7 \\
\hline
\end{tabular}

Tabela 6 - Ordenamento para o Tempo de Magistério ${ }^{12}$.

\begin{tabular}{cc}
\hline T. Magistério (anos) & $\begin{array}{c}\text { Escore de } \\
\text { ordem }\end{array}$ \\
\hline $0-5$ & 1 \\
$6-10$ & 2 \\
$11-15$ & 3 \\
$16-20$ & 4 \\
$21-25$ & 5 \\
$26-30$ & 6 \\
Mais de 30 & 7 \\
\hline
\end{tabular}

Tabela 7 - Ordenamento para o tempo em que o professor ministra aulas de Física

\begin{tabular}{cc}
\hline T. Física (anos) & $\begin{array}{c}\text { Escore de } \\
\text { ordem }\end{array}$ \\
\hline $0-5$ & 1 \\
$6-10$ & 2 \\
$11-15$ & 3 \\
$16-20$ & 4 \\
$21-25$ & 5 \\
$26-30$ & 6
\end{tabular}

${ }^{12}$ Classificação baseada no trabalho de Riggs e Enochs (1990). 
Tabela 8 - Ordenamento para Formação Acadêmica ${ }^{13}$.

\begin{tabular}{cc}
\hline Formação Acadêmica & Escores \\
\hline Física & 1 \\
Ciências Exatas $^{14}$ & 2 \\
Matemática & 3 \\
\hline
\end{tabular}

Tabela 9 - Ordenamento para Formação Complementar ${ }^{15}$.

\begin{tabular}{cc}
\hline Formação Complementar & Escores \\
\hline Possui & 1 \\
Não Possui & 0 \\
\hline
\end{tabular}

Na Tabela 10, apresentamos a tabela de validação do constructo.

Da Tabela 10, podemos concluir que existe uma correlação de 0,458 entre os níveis de CAEE e CAEP. Um valor bastante próximo para tal correlação foi apresentado por Enochs e Riggs (1990).

Além disso, observamos também que as CAEP possuem correlação com a carga horária semanal, o tempo ministrando aulas de Física e também a formação inicial do sujeito. Chama-nos a atenção a correlação negativa entre a carga horária semanal e a formação inicial docente com suas CAEP. Assim, podemos observar que os professores que ministram um número menor de aulas semanais e que possuem a Física como formação inicial indicam possuir maiores índices de CAEP. Além disso, a correlação positiva encontrada entre o tempo ministrando aulas de Física e as CAEP dos sujeitos revelam que quanto maior for essa variável, maior será a tendência em aumentar suas CAEP.

\footnotetext{
${ }^{13}$ É importante ressaltar que a Formação Acadêmica é uma variável nominal, assim a sua ordenação é completamente arbitrária. Dessa forma, nossa classificação para esse item foi baseada no trabalho de Silva (2007).

${ }^{14}$ Nas Ciências Exatas, estão dispostos os professores que possuem graduação em: Licenciatura e/ou Bacharelado em Química ou Biologia; Licenciatura em Ciências; Engenharia.

15 Consideramos formação complementar como um segundo curso de graduação, mestrado, doutorado, ou algum curso de especialização.
} 
Tabela 10 - Matriz de correlações entre as variáveis envolvidas na validação de constructo.

\begin{tabular}{ccccc}
\hline & CAEE & p-valor $^{16}$ & CAEP & p-valor \\
\hline CAEE & 1 &. & $0,458^{* *}$ & 0 \\
CAEP & $0,458^{* *}$ & 0 & 1 & $\cdot$ \\
Idade & 0,023 & 0,841 & 0,005 & 0,963 \\
Carga Horária & $-0,248^{*}$ & 0,028 & $-0,296^{* *}$ & 0,008 \\
Tempo de Magistério & 0,113 & 0,326 & 0,197 & 0,083 \\
Tempo - Física & 0,108 & 0,116 & $0,281^{*}$ & 0,013 \\
Formação & $-0,172$ & 0,132 & $-0,324 * *$ & 0,004 \\
Formação Complementar & 0,196 & 0,085 & 0,046 & 0,689 \\
\hline
\end{tabular}

Já as CAEE possuem correlação negativa somente com a carga horária semanal de aulas dos professores. É importante salientar que, embora as correlações apresentadas sejam significativas do ponto de vista estatístico, podemos concluir que as mesmas são correlações fracas, pois os índices apresentados no teste de Spearman são considerados baixos quando observamos os limites do teste +1 e 1.

As conclusões dispostas anteriormente nos permitem dizer que as hipóteses $2,3,5,6,8$ e 9 são consistentes. Sendo assim, findamos a última etapa de validação do instrumento de pesquisa, que nos permite concluir que este instrumento carrega consigo evidências de validade.

\section{Conclusões}

Concluímos que o questionário em questão é um instrumento sólido para a aferição tanto das crenças de autoeficácia geral no ensino como das crenças de

\footnotetext{
${ }^{16} \mathrm{O}$ p-valor (nível de significância estatística) é um índice utilizado para realizar um teste de hipóteses. Quanto menor for o p-valor calculado tanto mais remota é a possibilidade de que a hipótese nula seja verdadeira. Adotamos os usuais níveis de 0,05 e 0,01 , identificando-os como segue abaixo:

$*$ p-valor $<0,05$

$* *$ p-valor $<0,01$
} 
autoeficácia pessoal dos professores na inserção de tópicos de Física Moderna e Contemporânea. Dessa forma, este questionário pode ser atrelado a diversas outras metodologias e instrumentos de pesquisa que visem dar continuidade à busca pela compreensão das relações entre as crenças de autoeficácia dos professores, em especial aquelas que se referem à inserção de tópicos de Física Moderna e Contemporânea no Ensino Médio, e o seu comportamento.

Apesar dos questionários confeccionados em escala Likert apresentarem uma importante contribuição para o estudo das crenças de autoeficácia dos professores, gostaríamos de enfatizar que a associação desse instrumento com outros instrumentos de coleta de dados, de natureza qualitativa, como, entrevistas semiestruturadas, notas de campos e a apresentação de conflitos, podem trazer inúmeras contribuições para essa área de pesquisa através da triangulação dos dados, de modo, a compreendermos o papel das crenças de autoeficácia no comportamento humano ${ }^{17}$.

A consolidação desse instrumento de pesquisa nos possibilitou verificar o nível de CAEP e CAEE com relação à FMC dos sujeitos participantes desse estudo. Todavia, para compreendermos melhor o quanto essas crenças são relevantes para o trabalho desses professores em sala de aula, necessitamos associar tal instrumento com outros, citados anteriormente. A saber, em Rocha e Ricardo (2011) foi utilizada a metodologia qualitativa de pesquisa para aprofundar os aspectos quantitativos obtidos por meio da metodologia apresentada neste trabalho. Os recursos utilizados foram entrevistas semiestruturadas e situações-problema ${ }^{18}$, cujos resultados corroboram aqueles encontrados na abordagem quantitativa.

\section{Agradecimentos}

Os autores agradecem às importantes sugestões e às correções feitas pelos pareceristas anônimos.

\section{Referências bibliográficas}

ASHTON, P. T.; WEBB, R. B.; DODA, N. A study of teacher sense of efficacy: Final Report executive summary. Gainesville: University of Florida, 1983.

\footnotetext{
${ }^{17}$ Vide, Marques Filho (2011).

${ }^{18}$ Rocha e Ricardo (2013).
} 
ASHTON, P. T. Teacher efficacy: a motivational paradigm for effective teacher education. Journal of Teacher Education, v. 35, n. 5, p. 141-152, 1984.

CAVALCANTE M. A. O ensino de uma nova física e o exercício da cidadania. Revista Brasileira de Ensino de Física, v. 21, n. 4, p. 550-551, dez. 1999.

ATKINSON, J. W. Motivational determinants of risk-taking behavior. Psychological Review, v. 64, p. 359-372, 1957.

BANDURA, A. Self-efficacy: toward a unifying theory of behavioral change. Psycological Review, v. 84, n. 2, p. 191-215, 1977.

BANDURA, A. Recycling misconceptions of perceived self-efficacy. Cognitive Therapy and Research, v. 8, p. 231-255, 1984.

BANDURA, A. Self-efficacy. In: Social foundations of thought and action: a social cognitive theory. Englewood Cliffs: Prentice hall, 1986. p. 390453.

BANDURA, A. Evolution of social cognitive theory. In: SMITH, K. G.; HITT, M. A. (Eds.). Great minds in management. Oxford University Press, p. 9-35, 2005.

BEMBENUTTY, H. Teachers' self-efficacy beliefs, self-regulation of learning, and academic performance. In: AMERICAN PSYCHOLOGICAL ASSOCIATION, 2006, New Orleans. Disponível em:

<http://www.eric.ed.gov/PDFS/ED492947.pdf>. Acesso em: 20 nov. 2012.

BRASIL. Parâmetros Curriculares Nacionais para o Ensino Médio. Ministério da Educação/Secretaria da Educação Média e Tecnológica, Brasília, 1999.

BRASIL. PCN+ Ensino Médio: Orientações Educacionais Complementares aos Parâmetros Curriculares Nacionais para o Ensino Médio. Ciências da Natureza, Matemática e suas Tecnologias. Ministério da Educação/Secretaria da Educação Média e Tecnológica, Brasília, 2002.

BROCKINGTON, G. A realidade escondida: a dualidade onda-partícula para estudantes do Ensino Médio. 2005. 268f. Dissertação (Mestrado em Ensino de Ciências) - IFUSP/FEUSP, Universidade de São Paulo, São Paulo. 
BZUNECK, J. A. Crenças de autoeficácia de professoras do primeiro grau e sua relação com outras variáveis de predição e de contexto. Arquivos brasileiros de psicologia, vol. 48, n. 4, p. 57-89, 1996.

BZUNECK, J. As crenças de autoeficácia dos professores. In: SISTO, F. F.; OLIVEIRA, G. C.; FINI, L. D. T. (Orgs.). Leituras de Psicologia para Formação de Professores. Petrópolis: Vozes / Bragança Paulista: Universidade São Francisco, 2000. p. 117-134.

BZUNECK, J.; GUIMARAES, S. E. R. Crenças de eficácia de professores: validação da escala de Woolfolk e Hoy. Revista Psico-USF, v. 8, n. 2, p. 137-143, 2003.

ÇAKIROGLU, J.; ÇAKIROGLU, E.; BOONE, W. J. Pre-service teacher selfefficacy beliefs regarding science teaching: a comparison of pre-service teachers in Turkey and the USA. Science Educator, v. 14, n. 3, p. 31-40, 2005.

COLADARCI, T. Teachers' sense of efficacy and commitment to teaching. Journal of Experimental Education, v. 60, n. 4, p. 323-337, 1992.

CRONBACH, L. J Coefficient alpha and the internal structure of tests. IN: MEHRENS, W A.; EBEL, R. L. Principles of educational and psychological measurement. Chicago: Rand McNally, 1967.

DENZINE, G. M.; COONEY, J. B.; MCKENZIE, R. Confirmatory factor analysis of the teacher efficacy scale for prospective teacher. British Journal of Educational Psychology, v. 75, p. 689-708, 2005.

ENOCHS, L. G.; RIGGS, L. M. Further development of an elementary science teaching efficacy belief instrument: a preservice elementary scale. School Science and Mathematics, v. 90, n. 8, p. 694-706, 1990.

EREN, A. Examining the teacher efficacy and achievement goals as predictors of turkish student teachers' conceptions about teaching and learning. Australian Journal of Teacher Education, v. 34, n. 1, p. 69-87, 2009.

FREGONEZE, G. B. Crenças de autoeficácia de professores em situação de alterações curriculares no ensino médio. 2000. 118 f. Dissertação (Mestrado em Educação) - Centro de educação, comunicação e artes, Universidade estadual de Londrina, Londrina. 
FRIEDMAN, I. A.; KASS, E. Teacher self-efficacy: a classroom-organization conceptualization. Teacher and Teaching Education, v. 18, p. 1-12, 2002.

GIBSON, S.; DEMBO, M. H. Teacher efficacy: a construct validation. Journal of Education Psychology, v. 76, n. 4, p. 569-582, 1984.

GODDARD, R.; HOY, W.; HOY, A. W. Collective teacher efficacy: its meaning, measure, and impact on student achievement. American Educational Research Journal, v. 37, n. 2, p. 479-50, 2000.

GOYA, A.; BZUNECK, J. A.; GUIMARAES, S. E. R. Crenças de eficácia de professores e motivação de adolescentes para apreender Física. Revista Semestral da associação Brasileira de Psicologia Escolar e Educacional (ABRAPEE), v. 12 , n. 2, p. 51-67, 2008.

GUSKEY, T. R.; PASSARO, P. D. Teacher efficacy: a study of construct dimensions. American Educational Research Journal, v. 31, n. 3, p. 627-643, 1994.

LIKERT, R. Una tecnica para medir actitudes. In: SUMMERS, G. F. (Ed.) Medicion de actitudes. México: Editorial Trilias, 1976. p. 182-191.

LOCATELLI, A. C. D. A perspectiva do tempo futuro como um aspecto da motivação do adolescente na escola. 2004. 160f. Dissertação (Mestrado em Educação) - Universidade Estadual de Londrina, Londrina, Paraná.

LUPPI, M. A. R. As crenças de eficácia de professoras do Ensino Fundamental em diferentes contextos escolares. 2003. 97f. Dissertação (Mestrado em Educação) - Universidade Estadual de Londrina, Centro de Educação, Comunicação e Artes, Londrina.

MAROCO, J.; GARCIA-MARQUES, T. Qual a fiabilidade do alfa de Cronbach? Questões antigas e soluções modernas? Laboratório de Psicologia, n. 4, p. 65-90, 2006.

MARQUES FILHO, E. C. Crenças de futuros professores de Física em contexto de Inovação Curricular: $O$ caso de um curso de Física Moderna e Contemporânea no Ensino Médio. 2011. 418f. Dissertação (Mestrado em Ensino de Ciências) - Universidade de São Paulo, São Paulo.

MARZILLIER, J. S.; EASTMAN, C. Continuing problems with self-efficacy theory: a reply to Bandura. Cognitive Therapy and Research, v. 8, p. 257-262, 1984. 
MCCLELLAND, D. C. How motives, skills, and values determine what people do. American Psychologist, v. 40, p. 812-825, 1985.

MOREIRA, M. A. Pesquisa em ensino: o Vê epistemológico de Gowin. São Paulo: Pedagógica e Universitária Ltda, 1990.

NUNNALlY, J. C. Phychometric theory. New York: McGraw-Hill, 1967.

OSTERMANN, F.; RICCI, T. F. Conceitos de Física Quântica na formação de professores: relato de uma experiência didática centrada no uso de experimentos virtuais. Caderno Brasileiro de Ensino de Física, v. 22, n. 1, p. 9-25, 2005.

OSTERMANN, F.; MOREIRA, M. A. Uma revisão bibliográfica sobre a área de pesquisa em física moderna e contemporânea no ensino médio. Investigações em Ensino de Ciências, v. 5, n. 1, 2000. Disponível em:

<http://www.if.ufrgs.br/public/ensino/vol5/n1/v5_n1_a2.htm>. Acesso em: 14 out. 2012.

PAJARES, F. Self-efficacy Beliefs in Academic Settings. Review of Educational Research, n. 66, v. 4, p. 543-578, 1996.

PAJARES, F.; OLAZ, F. Teoria Social cognitiva e autoeficácia: uma visão geral. In: BANDURA, A.; AZZI, R. G.; POLYDORO, S. (Orgs.). Teoria Social Cognitiva: Conceitos Básicos. Porto Alegre: Artmed, 2008. p. 97-114.

PARKAY, F. W. et al. A study of relationships among teacher efficacy, locus of control, and stress. Journal of Research and Development in Education, v. 21, n. 4 , p. 13-22, 1988.

RIGGS, I. M.; ENOCHS, L. G. Toward the development of an elementary teachers science teaching efficacy belief instrument. Science Education, v. 74, n. 6, p. 625637, 1990.

ROCHA, D. M.; MARQUES FILHO, E. C. Auto-eficácia Docente: um novo instrumento para a medida das crenças de auto-eficácia dos professores sobre a inserção de tópicos de Física Moderna e Contemporânea In: SIMPÓSIO NACIONAL DE ENSINO DE FÍSICA, XIX, 2011, Manaus-AM. Anais do XIX Simpósio Nacional de Ensino de Física, 2011.

ROCHA, D. M.; RICARDO, E. C. Crenças de Autoeficácia e a formação docente em Física Moderna e Contemporânea: uma relação atuante nas práticas dos profes- 
sores. In: ENCONTRO NACIONAL DE PESQUISA EM EDUCAÇÃO EM CIÊNCIAS, VIII, 2011, Campinas. Anais do VII Encontro Nacional de Pesquisa em Educação em Ciências - ENPEC, 2011.

ROCHA, D. M.; RICARDO, E. C. As Crenças de Autoeficácia e as Práticas Docentes: apresentando um novo instrumento qualitativo para análise das crenças de autoeficácia dos professores de física. In: SIMPÓSIO NACIONAL DE ENSINO DE FÍSICA, XX, 2013, São Paulo. Anais do XX Simpósio Nacional de Ensino de Física - SNEF, 2013.

ROTTER, J. B. Social learning theory. In: FEATHER, N. T. (Org.). Expectations and actions: expectancy-value models in psychology. Hillsdale, NJ: Erlbaum, p. 1982. p. 241-260.

SILVA, F. R. Análise das crenças de eficácia de professores de Física do Ensino Médio. 2007. 120 f. Dissertação (Mestrado em Ensino de Ciências e Educação Matemática) - Centro de Ciências Exatas, Universidade Estadual de Londrina, Londrina.

SILVEIRA, F. L. Validação de testes de lápis e papel. In: MOREIRA, M. A.; SILVEIRA, F. L. (Org.). Instrumentos de pesquisa em ensino e aprendizagem. Porto Alegre: EDIPUCRS, 1993.

SIQUEIRA, M.; PIETROCOLA, M. A Transposição Didática aplicada à teoria contemporânea: A Física de Partículas elementares no Ensino Médio. In: ENCONTRO DE PESQUISA EM ENSINO DE FÍSICA, X, 2006, Londrina. Anais... v. 1, p. 1-1, 2006.

SMOLLECK, L. A.; YODER, E. P. Further Development and Validation of the Teaching Science as Inquiry (TSI) Instrument. School Science and Mathematics, v. 108, p. 291-297, 2008.

TSCHANNEN-MORAN, M.; HOY, A. W. Teacher efficacy: capturing an elusive construct. Teaching and Teacher Education, v. 17, p. 783-805, 2001.

WOOLFOLK, A. E.; HOY, W. K. Prospective teacher's sense of efficacy and beliefs about control. Journal of Educational Psychology, v. 82, n. 1, p. 81-91, 1990. 